\title{
Are Solution Manuals Detrimental to Student Learning?
}

Dr. Mohammad Habibi P.E., University of Wisconsin-Platteville Annelise Shirley Roti Roti, University of Wisconsin - Platteville Motahareh Alaei, Minnesota State University, Mankato 


\title{
Are Solution Manuals Detrimental to Student Learning?
}

\begin{abstract}
Homework has traditionally been the essential part of student learning, especially in engineering education. However, the availability of solution manuals has affected this, as it now takes just a few minutes to find solutions for specific homework problems on the internet. There are a number of papers reporting the effects of solution manuals on students' learning. Some of these reports argue that the availability of solution manuals has adversely affected student learning. Yet, there are two subjects in this area that have not been emphasized: students' perspectives toward solution manuals and the best options for instructors. Two surveys, one for students and one for faculty, were designed and submitted to the members of the College of Engineering, Mathematics and Science at the University of Wisconsin-Platteville. A total of 337 responses from students and 37 responses from faculty were received. According to the results of the collected survey, the majority of respondents believe that solution manuals help them to be more motivated, learn at a deeper level, and earn better grades. Faculty survey results also show that solution manuals can be helpful if they are used properly. This paper describes the results of the data collection.
\end{abstract}

\section{Introduction}

Homework is an essential part of learning in engineering education. Most engineering faculty and students believe that just attending the lectures is not enough for students to master the material, thus homework and projects are assigned to help student learning ${ }^{1}$. Walberg et al. reported that homework has substantial effects on students' learning ${ }^{2}$. They stated that assigning homework increases student learning by $10 \%$ and that if assigned homework is graded and proper feedback is provided, student learning improves by $30 \%$. Engineering students and faculty both believe that graded homework contributes to student learning ${ }^{3}$.

In recent years, the availability of homework solutions has been a major concern in engineering education $^{3,4,5,6}$. The use of solution manuals among students has increased from a few percent to more than $90 \%$ over last ten years ${ }^{4}$. Widmann et al. stated that engineering students reach a higher level of academic achievement if they do not use solution manuals ${ }^{5}$. This conclusion was based on homework and exam scores where scores were higher when students did not have access to solution manuals. 
In 2011, Karimi et al. investigated the effects of solution manuals on student learning by comparing grade distributions in thermodynamics courses. They reported that the percentage of students who earn lower grades ( D, F, and $\mathrm{W}$ ) in thermodynamics courses increases when students have access to solution manuals ${ }^{6}$.

Though there are a number of reports concerning negative effects of solution manuals on student learning, there are few reports which emphasize the positive effects. For example, Georgieva proposed a new method of teaching undergraduate mathematics in which the students are allowed free access to the complete solution manual ${ }^{7}$. The philosophy behind this approach is that homework should be used as an opportunity for students to practice and gain knowledge. Georgieva reported that the majority of students in their program did not use solution manuals for blind copying. All students in the classes improved their tests scores significantly and a remarkable increase in the students' motivations and interests was observed.

It also has been reported that if solution manuals are made available to students, they are less discouraged and intimidated by problems ${ }^{8}$. If not misused, solution manuals are a helpful resource that is available to students anywhere, anytime, without having to ask for it. With solution manuals available, students worked on more problems, both assigned and unassigned. Both papers ${ }^{7,8}$ report that some predicted negative consequences, such as less learning, copying without trying, etc., either did not happen or were negligible in comparison to the positive consequences.

Minichiello et al. replicated the study originally done by Widmann to clarify the nature of the inconsistency between engineering students and faculty opinions regarding the use of solution manuals ${ }^{4}$. Their results show that the majority of students use solution manuals after they tried to solve assigned homework on their own. This paper aims to describe faculty and students' perspectives regarding solution manuals.

\section{Methods}

\section{Sample Selection and Demographics}

The College of Engineering, Mathematics and Science (EMS) at the University of WisconsinPlatteville, with an enrollment of over 2500 and over 150 faculty and teaching staff, is one of the largest colleges across the state of Wisconsin. The college consists of nine academic departments: electrical engineering, civil and environmental engineering, chemistry, computer science and software engineering, engineering physics, general engineering, mathematics, mechanical engineering, and industrial engineering. The College of EMS offers ABETaccredited engineering degrees in civil, electrical, environmental, industrial, mechanical, and software engineering, as well as engineering physics. The college also offers degrees in mathematics, broad field science, chemistry, computer science, microsystems and nanomaterials, 
sustainable and renewable energy systems. We did not collect any demographic characteristics such as race, sex, age, year at school, etc.

\section{Survey Instrument and Respondents}

Two electronic surveys were created using www.surveymonkey.com: one was submitted to students across the college and one to the EMS faculty and teaching staff. The survey instrument was kept direct and brief since no effort was made to select potentially cooperative respondents and no compensation was paid for their participation. It was designed to be completed in less than 15 minutes. The student survey included six multiple choice questions and the faculty survey consisted of three. A combination of Likert-scale and open-ended formats was used so that the respondents' answers could be readily summarized statistically without being overly constrained. All questions on the students' survey presented multiple choices and accepted only one answer with the exception of question 1, in which they were able to select more than one answer. A comment box was also added to both surveys. The questions are shown in Tables 1 and 2.

Before sending the surveys to students and faculty, approval was obtained from the Institutional Review Board at the University of Wisconsin - Platteville to secure the participants' rights. A link to the survey and a consent form were emailed to the all students and faculty of the college through their department offices. The purpose of the consent form was to explain the research, describe how the confidentiality of participant would be protected, and to inform respondents that their participation was completely voluntary. A total of 334 students and 37 faculty responded to the survey. We do not know how many students and faculty received the surveys and/or were able to respond to them, as the data were collected during the week before final exams (Dec 9-18, 2014). The responses were collected anonymously and electronically using www.surveymonkey.com. Considering that there were no direct prizes or benefits to the participants, we believe that the research topic gained remarkable interest among students and faculty. Assuming all students and faculty in the college received and were able to respond to the surveys, $14 \%$ of students and $34 \%$ of faculty responded to the questionnaires; furthermore, many of participants provided comments in the provided space on the survey.

\section{Results and Discussion}

\section{A. Results from student' survey}

Why do students use solution manuals? According to the survey, using solution manuals seems very popular among engineering and science students since only about $2 \%$ of the participants indicated that they had not used them. Although most students' intentions is to use solution manuals to confirm their answers to homework or to learn solution processes by reading the author's approach, about half of students who use solution manuals try to gain full credit for their homework by copying answers to problems. It can be concluded from students' comments 
and the data presented in Figure 1 that students first try problems themselves but at the end they write correct answers to their homework.

Table 1. Student survey questions

\begin{tabular}{|c|c|}
\hline \multicolumn{2}{|l|}{ Student survey } \\
\hline $\begin{array}{l}\text { 1. I have used a solution manual for: } \\
\text { (you may choose more than one } \\
\text { answer) }\end{array}$ & $\begin{array}{l}>\text { Confirming answers to homework or practice problems } \\
>\text { Copying answers to homework for full credit } \\
>\quad \text { Learning solution processes by reading the author's approach } \\
\end{array}$ \\
\hline $\begin{array}{l}\text { 2. How did you do in a class where } \\
\text { you did not have access to/did not use } \\
\text { a solution manual? }\end{array}$ & $\begin{array}{l}>\text { I did well without a solution manual and without outside help. } \\
\text { I did well because I got outside help such as a tutor or study group. } \\
\text { I did okay without a solution manual. } \\
>\text { I did poorly without a solution manual. }\end{array}$ \\
\hline 3. Use of a solution manual aided... & $\begin{array}{l}>\text { Both my grade and my learning } \\
>\quad \text { My grade but not my learning } \\
>\quad \text { My learning but not my grade } \\
>\quad \text { Neither my grade nor my learning }\end{array}$ \\
\hline $\begin{array}{l}\text { 4. Overall, how do you think solution } \\
\text { manuals affect student learning? }\end{array}$ & $\begin{array}{l}>\text { They're helpful } \\
>\quad \text { They're hurtful } \\
\text { Depends on the course and instructor } \\
\text { No effect. }\end{array}$ \\
\hline $\begin{array}{l}\text { 5. If I could decide how homework } \\
\text { was assigned and graded, }\end{array}$ & $\begin{array}{l}\text { Problems come from (Textbook, Unknown sources, Instructor's } \\
\text { written) } \\
>\quad \text { Problems are graded (Always, Never, Sometimes) } \\
\text { Solutions available? (Yes, No, After homework is turned in) }\end{array}$ \\
\hline $\begin{array}{l}\text { 6. Do you think it is ethical for } \\
\text { students to use solution manuals? }\end{array}$ & $\begin{array}{l}\text { Yes } \\
\text { Yes, but only if it is used for learning and not just copying } \\
\text { No } \\
\text { I don't know }\end{array}$ \\
\hline Comments & \\
\hline
\end{tabular}

Table 2. Faculty survey questions

\begin{tabular}{|l|l|}
\hline Faculty survey & \\
\hline 1. Use of solution manuals has a & $>$ Strongly Agree \\
damaging effect on student learning. & $>$ Agree \\
& $>$ Disagree \\
& $>$ Strongly disagree \\
\hline $\begin{array}{l}\text { 2. What is the best method to optimize } \\
\text { student learning with the knowledge } \\
\text { that they have access to solution }\end{array}$ & $>$ Assign homework but do not collect/grade much of it, thus \\
manuals? & $>$ Create custom-made homework so students can not use solution \\
& $>$ manuals. \\
\hline $\begin{array}{l}\text { 3. Do you use the "best method" that } \\
\text { you chose above in your classroom? }\end{array}$ & $>$ Others: comment box to enter \\
\hline Comments & $>$ Sometimes \\
\hline
\end{tabular}




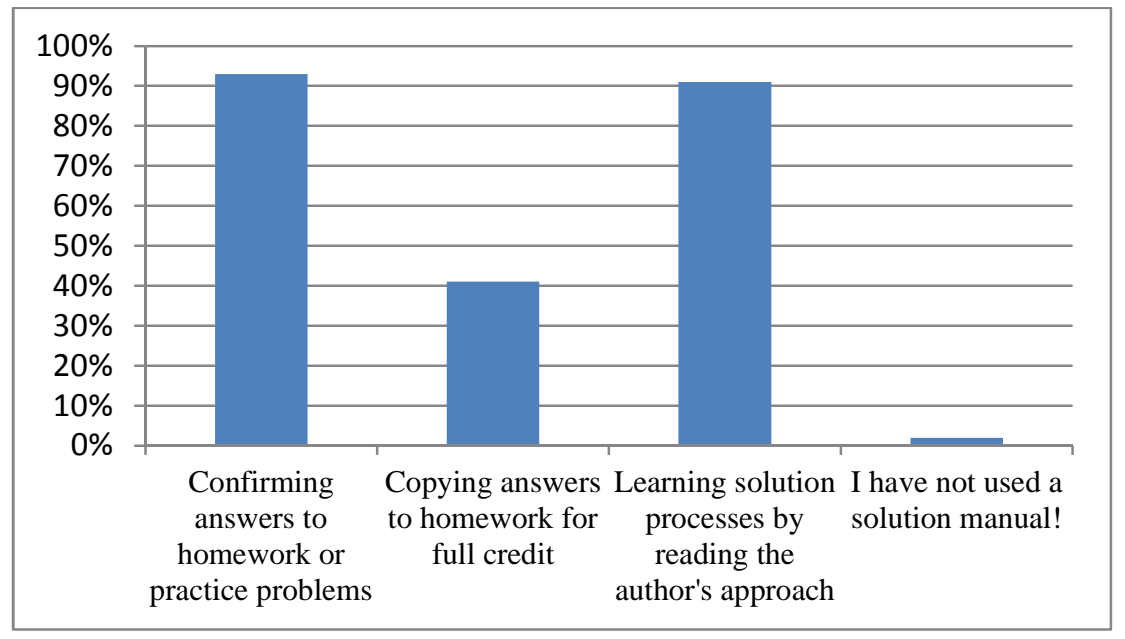

Figure 1. Students motivation vs \% of respondents

How did students do in a class where they did not have access to/did not use a solution manual? The results as shown in Figure 2 indicate that students adapt themselves to the class when they do not have access to solution manuals. They fill any gap in their learning by forming study groups, seeking outside help, or visiting faculty more often. Despite this, students do better in classes where homework is assigned from the textbook and graded with access to solution manuals.

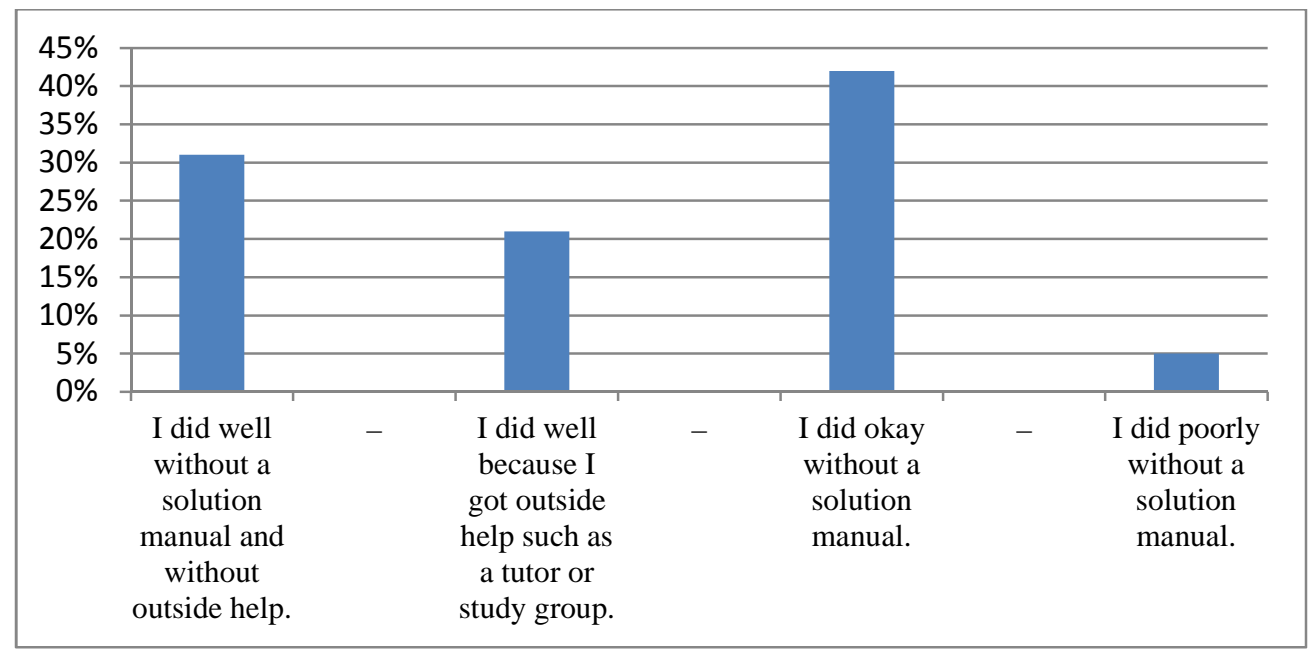

Figure 2. Students' performance to the class where they did not use solution manuals vs \% of respondents

Do solution manuals aid student learning or only help them to get a better grade? The majority of respondents believe that solution manuals aided both their learning and grades. Students believe that the path to answers is important and that solution manuals are instrumental in understanding the problem-solving process. Many of them commented that faculty do not have time to cover all the details in lectures and have limited office hours, therefore the only help 
that is available to them at any time is step by step solution to the problems. Students' comments also show that they come to understanding that copying the answers will help neither their learning nor their grades, so they should try the problem first.

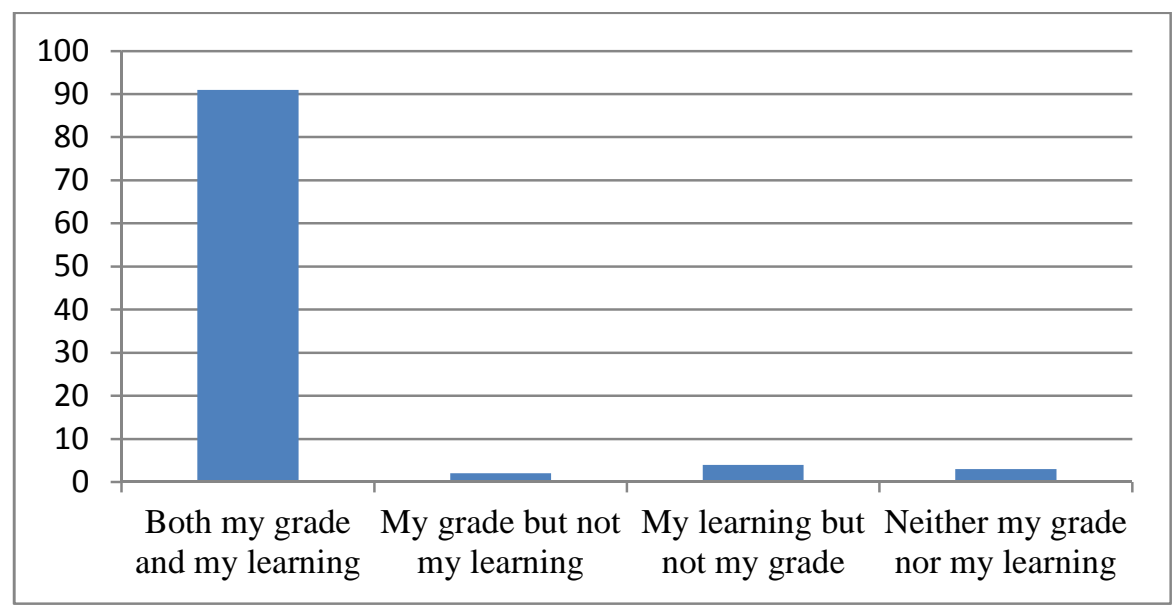

Figure 3. Students' response to effects of solution manuals on student learning and grade

How do students think solution manuals affect their learning? Only $1 \%$ of respondents indicated that solution manuals are detrimental to their learning as indicated by Figure 4 . The majority of students strongly believe that problem solutions are useful tools or at least understand that abusing solution manuals can hurt their learning. As students indicated in their comments, the answer to this question depends on both students and instructor. The authors believe that instructors have the chance to turn solution manuals into advantageous tools.

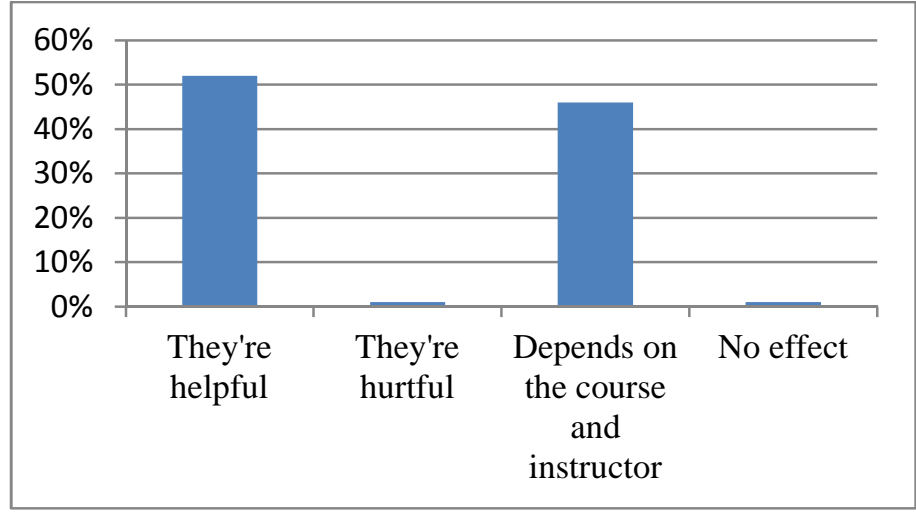

Figure 4. Students' opinions toward solution manuals

What are the students' preferences toward homework? The majority of student respondents prefer that homework be assigned from the textbook (74\%) or written by the instructor (19\%). They also prefer that homework be always graded (62\%) or at least sometimes graded (34\%). Most students would like the solution manuals to be available $(68 \%)$ or be available after 
homework turned in (30\%), as seen in Table 3. These results show that students want, at the very least, to be able to check their homework answers and have them graded often.

Table 3. Students' preferences toward homework

\begin{tabular}{|c|c|c|c|}
\hline \multicolumn{4}{|l|}{ I would prefer that... } \\
\hline & Textbook- & Unknown- & Instructor's written- \\
\hline Problems are assigned from... & $74.23 \%$ & $7.22 \%$ & $18.56 \%$ \\
\hline \multicolumn{4}{|l|}{ I would prefer that... } \\
\hline & Always- & Sometimes- & Never- \\
\hline Problems are........graded & $62.00 \%$ & $34.00 \%$ & $4.00 \%$ \\
\hline \multicolumn{4}{|l|}{ I would prefer that... } \\
\hline & Yes & No & $\begin{array}{l}\text { After homework } \\
\text { is turned in }\end{array}$ \\
\hline Solutions available? & $68.00 \%$ & $2.00 \%$ & $30.00 \%$ \\
\hline
\end{tabular}

Is it ethical for students to use solution manuals? Some faculty believe that the use of solution manuals before turning in homework is a type of cheating. In contrast, students believe that this use is only cheating if they just copy the answers for full credit. The main reason for this inconsistency is that students think of homework as a learning tool while some faculty use homework as an assessment tool. In the authors' opinions, homework is really both a learning and assessment tool and should be viewed this way by both students and faculty. The authors also believe that students have a good understanding what would be considered cheating when it comes to homework. Figure 5 exhibits students' responses to this question.

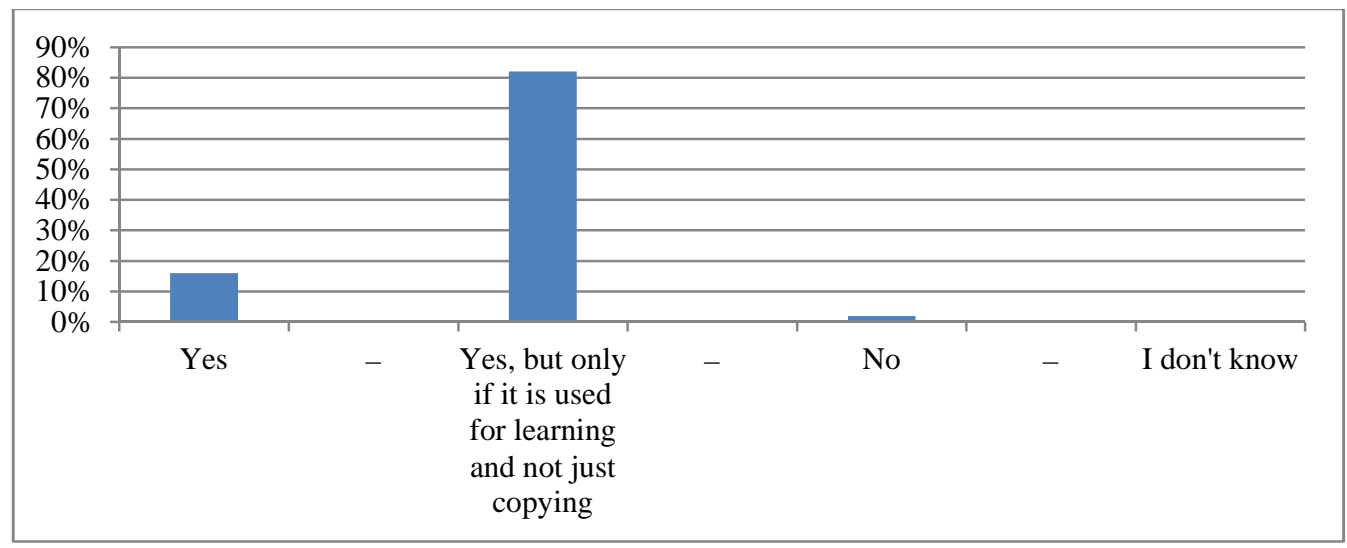

Figure 5. Percentage of respondents' answer to the question: Is it ethical for students to use solution manuals? 


\section{B. Results from faculty survey}

\section{Use of solution manuals has a damaging effect on student learning.}

As indicated in literature, faculty traditionally believe that solution manuals have a damaging effect on student learning and use of solution manuals is a type of cheating. The results of this survey question indicate that faculty have accepted the fact that problem solutions are available and students can easily access them. The focus is now how to make the best of the situation and look at solution manuals as a learning tool. As Figure 6 indicates, there is no strong opinion regarding the possible damaging effects of solution manuals on student learning among faculty.

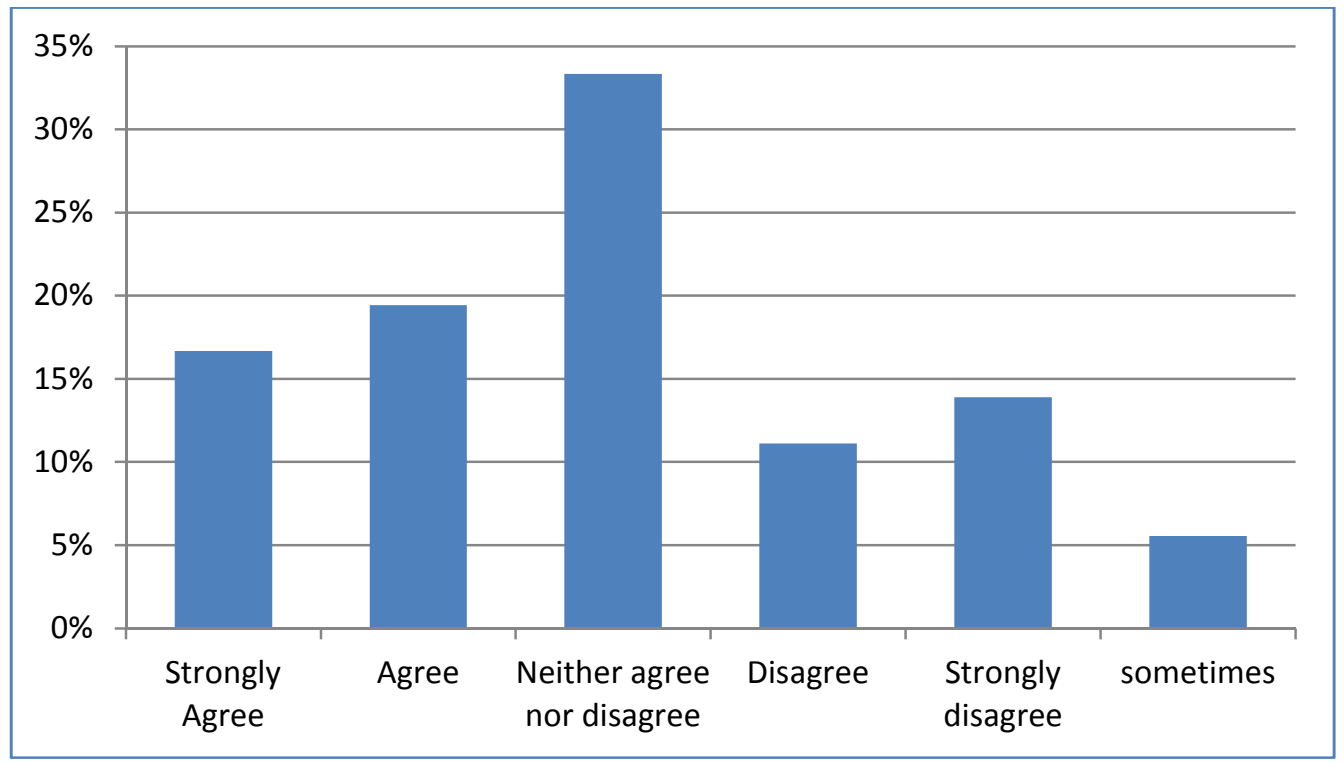

Figure 6. Faculty's opinion toward possible damaging effects of solution manuals on student learning

Faculty still believe that homework is an essential part of learning for engineering and science students. Less than $4 \%$ of faculty suggested that the use of homework should be eliminated because students have the solution. Most faculty respondents $(67 \%)$ create their own custom homework so that students cannot use solution manuals. This method is effective but requires significant amount of faculty time, and after a couple of semesters the solutions will be distributed among students if instructors post the solutions or solve the questions in class. Another approach is to assign homework but not collect or grade much of it, thus lowering homework's weight in the overall grade (30\%). Due to faculty workload, only $65 \%$ of faculty apply their self-described best method of practice. 


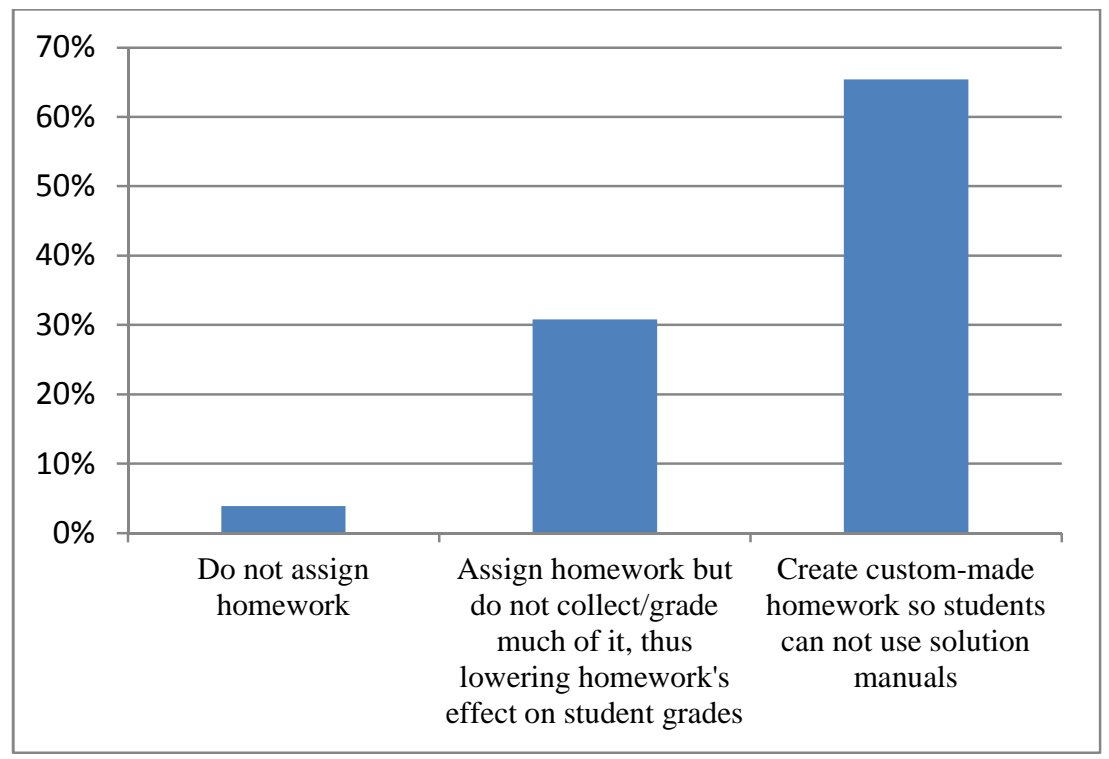

Figure 7. Faculty response to question: What is the best method to optimize student learning with the knowledge that they have access to solution manuals?

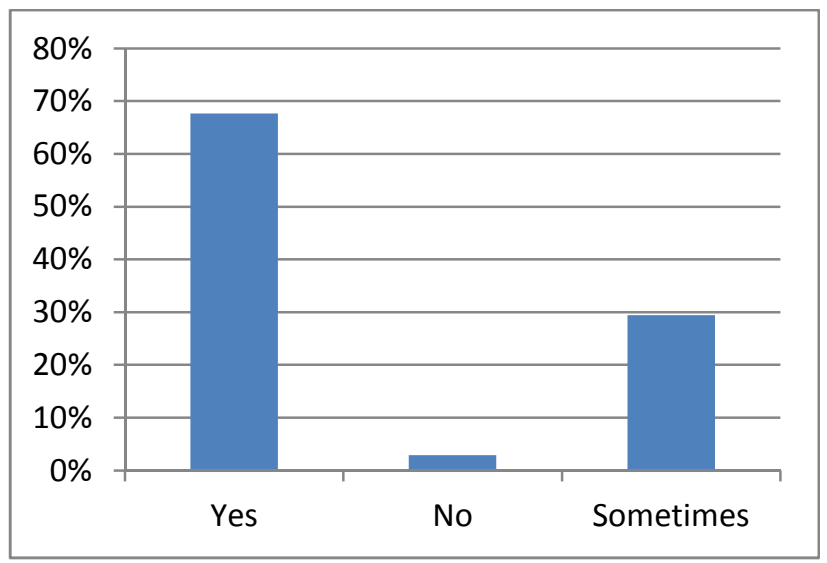

Figure 8. Faculty response to the question: Do you use the "best method" that you chose above in your classroom?

\section{Randomly selected student and faculty comments}

More than half of student respondents (175 out of 334) left comments in the comment box. A random selection of their comments can be found in the appendix section of this paper. The comments were copied directly without any editing by the authors. Less than half of faculty respondents (15 out of 37) also left comments in the comment box. The selected comments are in the Appendix. 


\section{Conclusions}

The main objective of this paper is to present the data and leave the conclusion to readers. However, the authors would like to express their personal experience regarding the availability of solution manuals:

- Not assigning homework has more damaging effects on student learning than solution manuals.

- Homework should be considered as a learning tool and its effects on students' grades should be minimized assuming students are able to copy answers for gaining full credits.

- As students indicated, problem solutions can be very helpful if they are used properly.

- If instructors allow their students to use solution manuals, the students are less intimidated by problems and more motivated to use faculty office hours efficiently.

- Solution manuals could potentially have damaging effects on student learning, if the student does not spend enough time to solve a problem. Therefore, the effective use of a solution manual should be taught in the class.

The authors acknowledge that respondents in a survey on such a controversial topic have the potential to be skewed. Further research of similar nature with larger focus groups should be conducted to negate any student biases present in surveys.

\section{References}

1. Habibi M., Ulseth R. Carlson M., "Developing design courses in a project-based curriculum," Proceedings of the 2012 American Society for Engineering Education Annual Conference \& Exposition, Atlanta, GA, 2013.

2. Walberg, H. J., Paschal, R. A., Weinstein, T., "Homework's Powerful Effects on Learning," Educational Leadership, Vol. 42, No. 7, pp. 76-79, 1985.

3. Widmann, J. and Shollenberger, K., "Student Use of Textbook Solution Manual: Student and Faculty Perspective in a Large Mechanical Engineering Department," ASEE2006-756, Proceedings of 2006 ASEE Annual Conference, Chicago, Illinois, 2006

4. Minichiello, A., McNeill, L., Hailey C. ," Comparing Engineering Student Use of Solution Manuals and Student/Faculty Perceptions of Academic Dishonesty," Proceedings of the 2012 American Society for Engineering Education Annual Conference \& Exposition, San Antonio, TX, 2012

5. Widmann, J. Shollenberger, K., Kennedy, J.K, "Student Use of Author's Solulion Manuals: Effect on Student Learning of Mechanics Fundamentals," ASEE2007-726, Proceedings of 2007 ASEE Annual Conference, Honolulu, Hawaii,2007. 
6. Karimi, A., Manteufel, R."Does Student Access to Solution Manual Pose a Challenge?" Proceedings of the 2011 American Society for Engineering Education Annual Conference \& Exposition, Vancouver, Canada, 2011

7. Georgieva B., "New approach to the use of solution manuals in the teaching of higher mathematics," Proceedings of the $2^{\text {nd }}$ International Conference on the Teaching of Mathematics at the Undergraduate Level, Crete, Greece, July 2002.

8. Ginsberg E., Panasuk R., George S., " Survey of Physics Instructor Attitudes on Student Access to Problem Solutions," Electronic Journal of Science Education, v2 n3 Mar 1998

\section{Appendix}

\section{Student comments}

"Solution manuals are not helpful at all if students just copy the answers. I have used solutions manuals and it has helped me out a lot. I use them to double check my answers as well as the way that I get to my answer. It helps to reinforce ideas as well as double check for simple mistakes. It is also helpful if you are stuck on a problem and just need figure out where to get started and not see the whole solution."

"If I do not know how to approach a problem it helps when I take a look at a solution manual to get on the right track. I think if I only see the right way to do a problem and the pattern they take, I am less likely to remember do it the wrong way next time."

"Depending on the solution manual and the provided answers in it they sometimes can't assist in the learning process. I like doing problems than referring back to the solution to confirm answers and help master a skill. Poor teaching from lecture also plays a factor. Students learn material from the solution manuals." "I do not advocate direct copying from a solutions manual, but do feel that I would not be here without either a tutor's help or the use of a solutions manual."

"In my experience, the temptation to just copy is very strong with solutions manuals, but for me they are extremely helpful. I have only used one solution manual for a difficult class, and I found that ( as long as I had the will to at least attempt the problem myself first ) I was able to learn the correct process for solving each problem and remember it much better because I could instantly correct my thinking processes. If you are considering supplying manuals for homework, I think it would be most effective to supply a complete solution including calculations for approximately half of the assigned homework problems, but not all."

"Manuals definitely help for a tough problem or when you're stuck. Office hours are not always compatible with a student's schedule. Homework is generally not a significant portion of your grade, so if you're using the manual to just copy answers, it usually shows on the exams. I use manuals to work through problems and understand how they're being done, its an individual and convenient way to learn."

"I believe that solution manuals give the student the ability to check each step that they do on a problem. A young students confidence is not always at a high after being taught the material in class. Solution manuals help in that regard. For others it may do more harm than good. It really is a case by situation"

"I have done very well at Platteville as a student with and without a solution manual. However, I have had much more frustration in classes trying to complete homework that I don't have the answers for. I think that for homework, answers should always be given, but it is okay to hide the solutions until after the homework is graded. This way the student knows that he is right if he can get the answer, but still has to show his work to get credit. I really believe that it comes down to the instructor. If he is good at knowing his course and his students, he will know when he should provide solutions, when to provide answers, and when to make the students do the work without and indication of whether or not they are correct."

"Let me use thermodynamics as an example sake. Could I have done the course without a solution manual? Certainly. Would it have really sucked? YES. Does a solution manual help me learn the topics faster and more effectively by getting me started in setting up and understanding equations? YES. There are a lot of problems in that course where you can get stuck by missing something very simple. Tutors and Instructors were rarely available to help at the times I was working on these assignments, so that's where the solution manuals come in handy to reference.. In regards to people copying it directly to turn in as a full credit 
assignment, I do not find that right, but guess who is going to be the ones doing poorly on exams? You guessed it, the ones who copied directly from the solutions manual.. If you copy material directly for homework to avoid learning and studying it, you will pay for it in your grade eventually. With how engineering professors typically have their grade percentages allotted, if you don't do well on exams (even if you ACE the homework from copying) you typically wont pass the course."

"I have used solution manuals many times. If you use them intelligently they can be very helpful. A lot of the time students are working on homework at night when instructors are not available so there is no way to get help if you get stuck. I agree that if you just copy the steps and answers you are hurting yourself assuming you don't go back and attempt to learn the material later. I did that in my sophomore year and it did hurt me. Now though I attempt the problem and when I get stuck I check the solution to see what step I need to take next then continue on my own. A lot of times you simply run out of time to attempt to do every single problem on your own. College cannot consist of purely school work, people would go insane and end up hating it all. I feel some instructors do not understand this and the fact that we take multiple courses at once."

"The real problem with solutions manuals is that students tend to abuse it. In all honesty, having the solutions to the problems is the most effective way to assign homework, in my opinion. This allows the students to check the answers and the professor to collect and verify that the students did it. The answers should always be correct but when learning the real benefit is not from the destination but the path to get there. That is where solutions manuals come in handy for those who know how to use them effectively and not just copy the solution as shown. If I resort to a manual, usually I will be stumped first. When I do, I quit that homework and move on to something else now that I know how to complete that problem and the process. I then come back to it tomorrow and try to reapply the solution method myself without it. So in this case, the manual is simply a reference. Homework is there to help the students and should be a small fraction of a grade, it is something that is more for our benefit, so to know how to do it is more valuable than trying and getting the process wrong only to find out once the homework is returned, what does one learn? Especially for those like me who find enjoyment in trying to deceiver the manual every once in a while because the author isn't always clear cut. It is almost an essential part of my learning process now. I could go on for days, sorry for the long reply. “

\section{Faculty comments:}

"Use custom-made homework in combination with on-line quizzes that are automatically graded"

"Some students use solution manuals to copy homework solutions so they do not have to work the problems themselves. This is poor use of the manuals. Others use the manual to understand the solutions to problems after they have made their best effort on the problems. This is good use of the manuals. I have had students in both categories in my classes."

"Let them practice with the textbook problems (and solutions manual). TEACH them how to study and solve problems. SHOW them that looking at the answers first is ineffective."

"Some students use solution manuals as a study aid. Other students copy the solution manual. Students that use solution manuals incorrectly do poorly on the exams."

"I don't have solution manuals to things that I assign for homework. So this is not a problem. I create custom assignments. But usually homework and quizzes count for $15-20 \%$ of the course grade."

"When you have mediocre students and below populating the program, and when such students use solution manuals, it is a recipe for disaster. I have no sympathies and fail them outright. Over the years, the number of A's in my class is less than $3 \%$, around 50\% flunk (D's and F's), and the rest are in low C's."

"I create problems in D2L that have randomized inputs. This challenges the students since they can't copy from each other, either."

"If students take the learning seriously, they are a great advantage to have the equations fully worked out. However, if students are just doing it to get it done, it is not useful."

"I also advocate mixing up homework (and I use this method) where about 70\% of a given homework assignment is custommade and $30 \%$ is from a textbook whose solutions manual they have. It ensures they receive direct guidance on the latter but then have to apply taught concepts to solve the former."

"Increasingly, students rely heavily on resources--manuals, previous exams, or other students--to the detriment of their own learning. Many do not even realize that they are NOT, in fact, learning but believe that, because they can find it on line or someone in their study group does understand the method that they, too, are competent. It's always worked and been rewarded. Some get quite upset if the game is changed." 
"Students must practice problem solving in order to learn the material. Too many students will not unless it directly, explicitly, contributes to their course grade and even then, will take the path which maximizes their grade while minimizing their effort."

"A student that do not independently solved problems without consulting the solution manual is self-deluded, building his knowledge of the subject on quicksand that will certainly crumble when he is faced with exam questions not tailored similar to the solution he copied."

"Solution manuals can be a valuable resource to students if used appropriately. I used them as a student, but did the homework first then used it to check. Students who just copy from the manual are plagiarizing and decreasing their opportunities to learn."

"As an instructor, it is my responsibility to bring students out of the comfort zone. When administering the homework with solution manual, students are kept in the comfort zone thereby hindering the learning process."

"assign plenty of problems with answers so they can find their way using the answers. have other problems and quizzes without answers that count as grades. both these scenarios can be used with online homework and D2L" 